\title{
RÉPLICA A: «LA OBRA EDUCATIVA DE DON VASCO DE QUIROGA, EN EL SIGLO XVI», DE MARVEYA VILLALOBOS PÉREZ-CORTÉS
}

Vasco de Quiroga es, sin duda, un actor clave para la formación de la Nueva España en el siglo XVI, parte indisoluble de la historia de Michoacán y pilar de la evangelización del Nuevo Mundo. Esto mismo ha propiciado que sea, también, un autor muy estudiado dentro de los múltiples temas de esa época; la bibliografía al respecto es amplia y el hecho de realizar un nuevo estudio sobre esta prominente figura resulta difícil desde el inicio.

Tratar de obtener un enfoque distinto a los muchos esbozados hasta ahora - evangelización, fundaciones políticas, hospitales-pueblo, historia de la Iglesia, etcétera - representa un reto para quien lo intente.

Para explicar esto más detalladamente, debo volver en el tiempo y recordar una investigación en la que tuve la fortuna de participar, hace casi diez años, como ayudante de investigación de Pablo Arce 
Gargollo, que dio como resultado un libro fundamental: Biografía y guía bibliográfica. Vasco de Quiroga. Jurista con mentalidad secular ${ }^{1}$, el cual publica — como apoyo para cualquier investigación sobre el primer obispo michoacano- una amplia lista de obras de diversos tipos (libros, artículos de revista, documentos...), que prácticamente abarcan todo lo publicado hasta ese año sobre el autor. Al final, encontramos 777 referencias y el propio Pablo Arce Gargollo ha ampliado esta lista con otras obras sobre Vasco de Quiroga, por lo que estamos por encima de 180 publicaciones.

Esto se menciona como marco desde el cual debe analizarse esta nueva publicación sobre Vasco de Quiroga y el juicio resulta muy favorable.

El capítulo «La obra educativa de don Vasco de Quiroga, en el siglo XVI» posibilita una revisión del obispo michoacano desde una perspectiva educativa y contemporánea: Marveya Villalobos Pérez-Cortés lee a Vasco de Quiroga desde una perspectiva globalizada, al igual que desde una visión multiculturalista, para aterrizar en una apreciación sobre la relación entre su idea del hombre y su idea de la educación.

El trabajo presentado puede ampliarse para afinar algunos puntos; es imposible tratar con plena profundidad el tema planteado en tan poco espacio. Este primer trabajo puede ser el detonante de una investigación más minuciosa que se presente a través de diversos artículos e incluso de un libro particular. El tema da sobradamente para ello debido a las múltiples disciplinas relacionadas en este tipo de proyectos. Así, pudo haberse presentado menos información bibliográfica de Vasco de Quiroga y abundar un poco más en los temas medulares que abren la investigación.

Algunos comentarios que señalaré pueden servir de aportaciones al tema investigado.

1 Arce Gargollo, Pablo (2007). Biografía y guía bibliográfica. Vasco de Quiroga. Jurista con mentalidad secular, $1^{a}$ ed., México: Porrúa-Universidad Panamericana. 
Si partimos de que Vasco de Quiroga no fue pedagogo - lo cual no anula que tuviera un plan definido sobre el funcionamiento y los métodos de enseñanza a emplear en los hospitales-pueblo-, sería útil explicar, desde el punto de vista de la filosofía de la educación o de la pedagogía, la aplicación de las estrategias que usó el obispo michoacano para la evangelización y la educación en el proyecto de los hospitales-pueblo.

Un punto importante a tratar, desde la metodología de trabajo, sería definir el método desde el cual se enfocará la investigación. Hasta ahora, uno de lo más útiles ha sido la hermenéutica analógica de Mauricio Beuchot, uno de los principales filósofos mexicanos de los últimos años y reconocido estudioso del pensamiento novohispano. Esto puede ser de gran utilidad si se realizara alguna comparación entre el siglo XVI y el XX, a partir de la globalización. El empleo de la analogía podría servir mucho a la investigación, tal como lo hace la filósofa Virginia Aspe Armella, quien en más de una ocasión se ha referido al siglo XVI como una primera globalización.

Esto nos lleva también al tema de la lectura multicultural que propone la autora. Considero que, efectivamente, la perspectiva multicultural permite entender muchos aspectos sociales de la Nueva España, pero también habría que explicar el sentido en el que se utilizarán algunos conceptos contemporáneos para relacionarlos con otra época tan lejana como el XVI.

Un concepto clave para la investigación sería: globalización o multiculturalismo. Respecto a la primera, cabría explicar si se entenderá como un proceso social abierto o excluyente, o bien, en qué sentido irá el universalismo implícito a ella y la relación que esto tiene con la diversidad cultural.

Otro tema derivado del proyecto de los hospitales-pueblo es el del autogobierno o el centralismo gubernamental. El experimento social de Vasco de Quiroga buscó no solo que los pueblos tuvieran autonomía política, sino también -y muy importante- económica; en ellos se enseñaban oficios que proporcionaran recursos económicos colectivos a la comunidad hospitalaria. Entre ellos estuvo el trabajo artesanal, que hasta nuestros días es característico de Michoacán, aunque con otras 
características. Debemos recordar que el proyecto inicial de Vasco de Quiroga tuvo un sentido muy práctico en ese aspecto, al no pensar en un simple proteccionismo real sino más bien en cierta autosuficiencia de las comunidades de los hospitales-pueblo. Pensando en nuestra época, se trata de un experimento por demás interesante y digno de analizarse.

A modo de conclusión, espero que la investigación se continúe y otras publicaciones nos permitan conocer a profundidad este aspecto de la vida y obra de Vasco de Quiroga.

Luis Aarón Patiño Palafox 